\section{B A Institute of \\ YK Business Administration \\ TK \\ Karachi \\ Leadership and Ideas for Tomorrow}

Business Review

Volume 4 Issue 2 July-December 2009

7-1-2009

\title{
Role of mass media in quality assurance of higher education in Pakistan
}

Sohaib Rabbani Khan

PAF-KIET, Karachi, Pakistan

Follow this and additional works at: https://ir.iba.edu.pk/businessreview

Part of the Educational Assessment, Evaluation, and Research Commons, Educational Leadership Commons, Educational Technology Commons, Higher Education Commons, Mass Communication Commons, and the Social Influence and Political Communication Commons

(c) (i)

This work is licensed under a Creative Commons Attribution 4.0 International License.

\section{Recommended Citation}

Khan, S. R. (2009). Role of mass media in quality assurance of higher education in Pakistan. Business Review, 4(2), 69-86. Retrieved from https://doi.org/10.54784/1990-6587.1332

This article is brought to you by iRepository for open access under the Creative Commons Attribution 4.0 License and is available at https://ir.iba.edu.pk/businessreview/vol4/iss2/6. For more information, please contact irepository@iba.edu.pk. 


\title{
ARTICLE
}

\section{Role Of Mass Media In Quality Assurance Of Higher Education In Pakistan}

\author{
Sohaib Rabbani Khan \\ PAF-KIET, Karachi, Pakistan
}

\begin{abstract}
Higher education is the ladder to economic prosperity in today's world. Quality in higher education indeed is the basic requirement for success of higher education institutions. But quality is never an accident, it is always the result of diligent work. During the last decade almost 50 universities / institutes of higher education have been established in the country. But the variations in quality of its graduates are too wide to accept.
\end{abstract}

The objectives of this research were to find out the role of mass media in improving the quality of higher education and how far the same can be improved. In this regard NGOs or management of the universities / institutes indeed play a very important role but without close monitoring and mentoring quality output cannot be guaranteed.

The findings show that the mass media particularly with the advent of Internet can play a pivotal role for quantum leap in higher education in Pakistan. The mass media can help in creating the awareness and in appreciating the benefits of higher education. Universities in general and private ones in particular need guidance and mentoring by the community and media about the demand and supply of educated workforce in particular disciplines. The low performing universities need to be encouraged and motivated to perform in a focused direction for increase output, both qualitatively as well as quantitatively.

In this paper key issues of higher education have been discussed where media can play its role. Solutions have been offered for accelerating quality standards in higher education.

Key words: Mass media, higher education, quality in higher education, media influence

NOTE:

This paper was read in the Interdisciplinary Social Sciences International Conference 2008 held on November 5-6, 2008 at Karachi; organized by Faculty of Arts, University of Karachi, Pakistan. 


\section{INTRODUCTION}

The great aim of education is not knowledge but action (Herbert Spencer, 1986, NA). It is on the sound education of people that the security and destiny of every nation chiefly rests. (Louis Kossuth, 1986, NA). But action can not be done without knowledge and knowledge cannot be perfected without quality and quality cannot be assured without competition. Competition is created through awareness and awareness is created through media. For quality assurance in higher education The International Network for Quality Assurance in Higher Education was formed in Hong Kong in 1991 by 18 quality assurance agencies. Now after almost 17 years there are about 150 member organizations, around 100 of which are quality assurance agencies (Woodhouse, 2006). Superior quality in education leads to social excellence, national excellence and academic excellence. (Moosa 2006). Three types of Quality Models are globally popular. These are Accreditation Model, Educational Excellence Award Model and Management Standards. (Moosa 2006). Mian Sarfraz (2006) has said that the role of entrepreneurial university is composed of teaching, research and innovation support. For research and innovation support is needed. This can be obtained from the Industry. Industry is in the lookout of highly qualified professionally competent workforce. It is concerned with the updated practical solution to the specific industry problem. There need to build a bridge between the higher education sector and the industrial sector.

The requirement of research for new products or services is explored and publicized. The new products or services must be better than the competition for a profitable market acceptance. Competition rises with spread of information and awareness. Higher the level of information to the end user tougher the competition will be. When competition increases quality improves. Information dissemination for quality and competition is the role of the media. Media has played major roles in changing lifestyles of modern times. It can change the expectations of education stakeholders (industry, parents and students) from the university.

\section{OVERVIEW}

The most important contributing factor for progress and prosperity of a nation is higher education. The nations who invested heavily in higher education reaped the reward decades later. There are 124 universities in Pakistan, 67 (53\%) in the public sector and 57 (47\%) in the private sector. But the students enrollment and pass out figures in these sectors are not in the same proportion. During the three year period $(2001-4)$ total students enrollment and total output were as follows (Table 1): 
TABLE 1

ENROLLMENT AND OUTPUT OF UNIVERSITIES IN PAKISTAN DURING 3 YEARS PERIOD (2001 - 2004)

\begin{tabular}{ll}
\hline Total enrollment (3 years) & $\mathbf{1 , 0 3 1 , 2 5 5 ( 1 0 0 \% )}$ \\
\hline Total Public sector enrollment (3 years) & $871,013(84.5 \%)$ \\
Each public sector university enrollment (3 years) & 13,197 \\
Per year average enrollment for each public university & 4,399 \\
Private sector enrollment (3 years) & $160,242(15.5 \%)$ \\
Each private sector university enrollment (for 3 years) & 2,861 \\
Per year average enrollment for each private university & 953 \\
Total output (3 years) (30.7\% of enrollment) & $\mathbf{3 1 7 , 0 8 8}(\mathbf{1 0 0 \% )}$ \\
Total public sector university output (3 years) & $288,508(90.9 \%)$ \\
Each public sector university output (3 years) & 4,371 \\
Per year average output for each public university & 1,457 \\
Total Private sector output & $28,580(9.1 \%)$ \\
Each private sector university output (3 years) & 510 \\
Per year average output for each private university & 170 \\
Total Enrollment for PhD (3 years) & $\mathbf{1 3 , 7 3 4}$ \\
PhD enrollment per years average & 4,578 \\
Output for PhD (3 years) & 811 \\
PhD output per year & 270 \\
PhD output per year per university (average) & $\mathbf{2}$ \\
\hline
\end{tabular}

(Based on statistics of Govt of Pakistan 2008)

Almost $30.7 \%$ of the total students (both public as well as private sector) enrolled are passed out at different stages. Almost $91 \%$ of the passed out students belong to Public Sector University while the remaining 9\% belong to the private sector universities. The pass out percentage for public sector was 33.1\% while for private sector it was $17.8 \%$. This enrollment and output include all the affiliated colleges and from undergraduate level to $\mathrm{PhD}$ level and all the programs that universities of Pakistan do offer. Now look at the PhD figures for the same period $(2001-2004)$. The output is only $5.9 \%$ of the enrollment or 2 scholars per year per university for the specified period. It is a point to mention at this place that the students enrolled in a particular year takes at least 2-3 years to pass out. That's the reason that we have taken a cumulative figure for three years. Time series analysis for a longer period could not be made because comparable figures for a longer duration were not available. 
It is interesting to see that as high as $41 \%(357,715)$ of the total students are enrolled through distance learning program. If we deduct this figure from the total figure it would be 673,540 . That means $(31 \%$ of 673,540$), 208,797$ students qualify through regular scheme from the undergraduate level to $\mathrm{PhD}$ level in 124 universities of Pakistan. Thus per university output is 1,683 students (for 3 years) and 561 students (for one year).

Realistically speaking this is a very depressing situation. The condition is further aggravated due to lack of participation interests by those who can contribute significantly e. g. Media. Historically it is proven that media can turn the direction of the history. It can create history. The war of independence, the disintegration of Soviet Union, the Gulf War, the War on Terror all are the products of very strong media campaigns. The US election of 2008 and the role that media played are ample proof that how and up to what extent the media can play its role in shaping the events. Media have also been playing very strong role in promoting culture as well. With reference to culture, there is a saying that culture invasion is boundary less and therefore can not be stopped. But the invasion rides on media. It is through media that culture of different nations at different times are voiced and awareness created. Thus media helps in the exchange and spread of diverse culture around the world.

Based on the findings of school leavers and enrollment at the undergraduate level of universities we see that a large number of students fail to continue their studies. Why so is anybody's guess and therefore is another research topic. However, a general idea based on prevailing conditions is the lack of financial support since child labor is still very common in Pakistan and the children need to contribute to the family income through their meager means. With the increase in awareness of higher education, more and more families like to acquire higher education for their children, but all of them cannot be accommodated in public sector universities and fees for private sector universities are too high. Education is the right of every citizen and if certain people cannot pay for their education then who should pay for them? A question very simple for common readers but for the affected students and their parents it is a very pertinent question. The need based scholarships offered by universities are too few to take care of the quantum want.

As Birrell and Edward (Birrell \& Edwards, 2007; Birrell \& Rapson, 2006) mentions that in Australia the need of increasing the number of government-funded places at Victorian universities over the next decade was expressed. The demand for such places exists, yet the continuing erosion of opportunity for disadvantaged students may mean that the desire to compete in such a tight market may wane, thus creating additional crises relating to Australia's relatively low education participation rate. Until governments (both State and Federal) and universities address the core issue of declining opportunity, the educational prospects of many disadvantaged students will not improve. (Edwards 2008). 
Another aspect of higher education seems that our universities mostly working in isolation, without much interaction with other universities. The universities need to be transformed from isolated islands to interactive forums. The process of transformation would include the integration of modern technology. Use of teaching aids e. g. multimedia and interactive methods like workshops, seminars etc should be a norm in a learning environment rather than compulsion. The learning should be community centered and empirical based on modern parameters. There has been a leadership role shifting. The emerging leadership role is more a capacity to contribute rather than capacity to dominate or dictate. A denial of acceptance for adaptation will only deprive us of the potential benefits it promises.

The tradition-bound academic priorities of the past century must be fundamentally revised. Academic knowledge must be the curricular resources to enrich human growth and development, and not to restrict control, dictate and frustrate basic needs for new learning. Teaching for human development must be seen as an ongoing exercise requiring continuous improvement keeping in line with other nations. Teachers, parents, the media and society impart knowledge directly and indirectly. A student is not successful unless he adapts to the urgent needs of the society to learn to live today and tomorrow in a complex, often frightening real world.

In the emerging need of the time each university must serve two masters - the learner and the larger society. If the school of the future continues to try to restrict, control and dictate what certain special interests want students to know, it will have little success and be relatively ineffective. However, universities of the future bringing students, universities, families and communities together in meaningful, satisfying ways thus can serve both individual learning needs and those of the larger society.

\section{ROLE OF MEDIA}

In the last 50 years the media influence has grown exponentially with the advancement of technology, first there was the telegraph, then the radio, the newspaper, magazines, films, television and now the internet. We have put our trust on the media as an authority to give us news, entertainment and education. However, the influence of mass media on our kids, teenagers, youth and society is so big that we should know how it really works. From the moment we wake up in the morning we are bombarded with media in all it's many forms. From the morning newspaper and it's many advertisements to the television commercials telling us what we need to buy. Even when we turn on the radio during our daily commute we feel overwhelmed with new mainstream 'music' full of vulgarities and rudeness that could put one in a bad mood for the entire day. Media has a major influence in our lives, whether people like to admit it or not. Most media out there are harmless, people simply trying to sell you their products to make a living or tell you the news. Although more often than we care to admit the media has harmful messages and influence over us. From the violent video games that have 
filled the market to the Internet, which is filled with negative information and themes. Many experts say we need to evaluate the media trend of today. Is the media creating a healthy nation with its all kinds of knowledge dissemination efforts, or it is just following the nasty trend of vulgarity and obscenity and leading us to a unconscious conscienceless society?

Who owns mass media in Pakistan? The Dawn group owns The daily 'Dawn' and monthly 'Herald' beside its news channel 'The Dawn News'. The Jang Group owns the daily 'Jang' (Unrdu), daily 'The News', evening daily 'The Daily News', English monthly 'Mag' and Urdu weekly 'Akhbar e Jahan'. The Jang Group owns the most viewed TV channel of Pakistan 'GEO'. Another media tycoon 'The Nation' Group owns 'The Nation' (daily), 'The Nawa e Waqt' (daily), weekly Urdu Magazine 'Family' beside its TV channel 'Waqt'. The three media giants own and virtually control the mass media in Pakistan. However in electronic media Pakistan Television has a wider coverage with its number of different channels. But with reference to political news and information its credibility has a question mark.

The media makes billions with the advertising they sell and that we are exposed to. We buy what we are told to be good, after seeing thousands of advertisings. We make our buying decisions based on what we see on TV, newspapers or magazines about a product. The decision is also based on what everyone else that we know is buying and whose decisions are equally based on the media influence.

It's very easy not to think, and to let the media shape our views. It's also very easy to get caught up in the emotions of what's happening, especially when the media is cultivating those emotions to get the response they want, either consciously or subconsciously. It's harder to shake that influence. The powerful media considers it appropriate to give what in their opinion the public should receive and not what they want. The media possesses so much power to influence that those in the media must be diligent about delivering news in a balanced manner that brings the story to the consumer with all sides fairly represented. Journalism is a profession like any other and certain standards of quality and professionalism need to be maintained. Media is often times used to convince massive amounts of people of something, almost a mass brainwashing. They can shape the public opinion in different ways depending of what is the objective. After the attack of 9/11 the media gave a huge coverage of the event and exposed Osama as the mastermind and key responsible person for the attack based on the briefing by the authorities. This shaped the public opinion to support the war on terrorism. This media campaign was followed by the propaganda of weapons of mass destruction (WMD) for Iraq and ultimately resulted in its invasion by the coalition forces and capture by United States of America. The problem is that if media received inaccurate information e. g. with reference to weapon of mass destruction in Iraq, media developed a wrong campaign and public opinion supported a wrong cause, this is the power of public opinion influence. (Ken Freed. Media Vision Journal. http://www.mediavisions.com/index.htm). The media shape our attitudes about everything from politics 
to education. Thus it is imperative that Pakistani media play its role in shaping the education culture in the country.

Radio has been used extensively as an educational medium in developing countries. Reports confirm that it has supported educational programs in a wide range of subject areas in many different countries. In India radio is used for rural development (Long, 1984). (Chelvan and Viswanathan 2006).

The most important member of the mass media is Television. Television has taken a prime position in our life. We have developed a false impression within ourselves. On the one hand we love to stick to the tube, on the other hand we claim that we don't do so. This duel nature has made our role ambiguous.

Watching TV is replacing real life with artificial reality. TV brainwashes us, displacing our native imagination with televised images. TV also imposes on us a set of biases that alienates us from others and ourselves. Television receiving sets are everywhere, and we watch TV a lot. We are a nation of television viewers. TV introduces violence and crime to our children. It teaches our children all the nuisances that used to be the curse only for the developed nations, but they have invaded into our culture as well. TV steals our time. TV has a hypnotic quality. Once the eyes and ears are glued to the idiot box, the mind gets engaged and hooked as well. TV reduces our attention span. When watching TV we lounge around like over baked sofa spuds while our lifework goes undone. TV tends to reinforce our basest instincts. Amid the many woes of our world, since most of us apparently want to be dumb or dumber, television caters to our desires to become comfortably numb. TV reduces our intelligence. Making sense of life is a challenge in any era. In our era of rapid social and technological change, mindless sex and violence on TV does not expand our capacity to reason. Mass-market TV tends to bolster idiocy. Most of us have lousy self esteem to begin with, so we're constantly looking outside of ourselves for validation that we're okay. TV programming and advertising tend to reinforce our addiction to external authority, the ads massaging our minds into imagining we'll be more popular if we buy certain products. The modern media is building media content transportation system incorporating digital antennas, cables, satellites, microwave dishes, optical fibers, copper wires, and even utility power lines. By building communication channels among people living in every land, we cultivate the soil for "interactivity" to flourish.

But TV and other interactive media can become a friend as well, look into how "distance learning" is revolutionizing world's school systems. Once students gain instant access to the best brains on earth, their horizons expand. The Internet and interactive TV services transcend the old tribal boundaries. A child today can download more information on the Web in an hour than our ancestors could learn in a lifetime. Media content may come from anywhere on the planet. That's genuine freedom! 
If people feel more connected with the world they feel more powerful. They have more self esteem and more incentive to take action about whatever they care about. When people feel they can have an impact on the world around them, they get more involved. They feel an investment in the society around them. Our rapidly changing world is a scary, confusing place these days. Why deny our natural fear of the unknown? We already hold inside all the power we need to transform the media and ourselves into a vital force for good in our world. Today in this 21 st Century, interactive media is a norm rather than exception. Today the medium is the massage. How TV messages massage our minds has been decided by TV being a one-way medium. But in the twoway TV now becoming possible, the medium massages the message as the message massages the medium. TV shapes us as we shape TV. What can we actually do that will make TV better? For better or worse, TV will become whatever we make it.

Television also has a responsibility to offer media content and services that elevates our lives and communities. But do they do what they should? We talk about computer literacy as the raw ability to operate the new digital devices. More recently, people are talking about 'media literacy' as the ability to think critically about media content. Both are vital skills. We need to know what should be the media content and why? If we are going to be smart TV users, children and adults alike need to be more aware of our power within the web of life. We need deep media literacy, consciousness of our common interactivity, so we make personal and community media choices for the highest good.

A civilized society is run on systems. There are four pillars of the systems. Political, economic, social and educational. We see that the former three are duly covered by the media but the last one education requiring greater emphasis and support is neglected and deprived of the media support, particularly in the developing countries like Pakistan.

What we need to be aware is that most of our decisions, beliefs and values are based on what we know for a fact, our assumptions and our own experiences. In our work we usually know what we have to do based on our experience and studies, however on our daily lives we rely on the media to get the current news and facts about what is important and what we should be aware of. (Ken Freed. Media Vision Journal. http://www.media-visions.com/index.htm)

Developing the interactive educational media market may be accelerated with high quality 'edutainment. The global infrastructure of interactive digital media is being constructed now. Many years of visionary thinking finally is starting to pay off. The PC and TV are converging. On the TV screen itself, electronic program guides are tested and ready to help us find and select any kind of content. As Freed rightly said (Freed. http://media-visions.com/ed-edutain.html) "The masses do want knowledge served with some entertainment, "edutainment," We now live in a frightened world struggling to 
cope with the "future shock" caused by so much innovation happening so fast. Interactive media may be the most powerful tool for our enlightenment. We owe it to our children to consider the social effects of what we do now. Will our decisions be guided by visions of hope? Will interactive media fulfill its highest and best potential? Will we stay true to our souls? Our choices today well make a difference tomorrow."

The higher education providers (i. e. the universities) cannot deliver excellence in isolation. They need the support of the societal active members among whom media is the foremost. The media on the other hand should be judicious enough to cover the education sector in general and higher education institutions in particular for promotion and persuasion. Based on the history and observation we see that media has played its role whenever it was felt that there is a need to do so. Media do support causes or issues on a local or individual basis as well. But unfortunately media support for the cause of education in Pakistan has not been adequate enough for sufficient impact resulting in improvement in enrollment and pass percentage. There has not been sufficient media coverage for educational activities and offerings e. g. convocation, result, conference, scholarship unless they are attended by hierarchies at the bureaucracy. This includes public sector universities as well. The recent updating in knowledge acquisition and future scope for knowledge utilization are not disseminated optimally. The students and parents remain disillusioned about the scope of any particular branch of higher education. One may argue that each university has its own website and information may be obtained from there. But the information available at the site are the version of the university itself and therefore not unbiased or impartial. Because of their origin they always have the colored representation. Mass media can help the stakeholders and beneficiaries (i. e., industry, students and parents) substantially. Students are acquiring business related degrees because most of the recent universities are not offering other programs to the same extent. The market is full of business graduates. Since the cost of the degree is very high, the students and parents expect a high payback as well. But as soon as their ward pass out and steps into the real world their dreams shatter and the frustrated ward submissively compromises on a low return because of limited employment opportunities for the disciplines. The program offerings of private universities mainly concern with low investment and high profitability particularly for commercially motivated private sector universities. Additionally, faculty for disciplines other than business and humanities are scarce too. Information about the prevailing trend in education around the world are not available to the parents or students in general. There is no way to know for a common man which university should be preferred over others and for which disciplines and for what reasons. Moreover, which discipline would make the careers of their wards more prosperous than others is also a dilemma for the parents.

In a western society there are ranking of universities every year. Private universities put a lot of efforts to be on the high ranking particularly by good and well established periodicals. But in Pakistan this has not been done yet. Though some grading of universities by the Higher Education Commission (HEC) of Pakistan is available the 
parameters are rather ambiguous. The comparative facilities and programs need to be disseminated to the students and the common man from a source other than the universities themselves and preferably by HEC. Media can play its role in this connection by highlighting the salient features of individual universities as they do so while briefing the company information periodically. On television there are programs on politics, social aspects, programs for kids including cartoon programs, sports channel, film channel, fashion channel etc. But there is hardly any education channel. There is hardly any program to motivate our youth for their academic achievements. WHO program for vaccination was widely publicized by media, sponsored or un-sponsored both. As a result of such high level consistent media support many killer diseases have been eradicated from the world (e. g. small pox, cholera etc). Higher education promotion need the same kind of media commitment to make Pakistan an educated nation, opening up of universities is not sufficient alone to impart higher education.

Media need to build a sense of ownership to facilitate change with reference to higher education. The Media need to be interactive. Technology -- specifically interactive one along with the new media can transform the higher education landscape completely. In our daily life television, radio, the Internet, cable network, mobile telephones and other wireless communication are available. In these media we see programs and advertising which are easily accessible to billions of people. Someone very rightly said, 'repetition works wonders'. Repeated exposure over time to similar messages makes it easy for people to accept them as true. Just consider how often television ads are repeated. The high impact of conveying repetitive message has been proven over time. Think also political messages, religious tenets, business decision making trends and economic ideas and it becomes obvious how, through simple repetition, the media influence our decisions. The needs and benefits of education acquisition and higher education in particular need to be voiced and repeated the same way through the media again and again.

\section{METHODOLOGY}

To assess the contribution, influence and impact of media on the mass population two research projects were undertaken. One was the desk research on media assessing the coverage of six prominent newspapers of the country. Another one was the survey of households of Karachi on the time spent by household ladies on a daily basis.

\subsection{MEDIA RESEARCH}

To assess the contribution of print media in promoting higher education a desk research was conducted. For this purpose six major daily newspapers were selected, three English and three Urdu. These are The Dawn, The News, The Nation, The Jang, The Nawa e Waqt and The Express. 
Coverage of these newspapers for two months from September1 to October 31st, 2008 was assessed on the following parameters:

- $\quad$ Political / social news coverage

- Business News (including industry real estate etc) coverage

- $\quad$ Entertainment/showbiz coverage

- $\quad$ Sports coverage

- $\quad$ Educational news/institutions coverage

Sponsorship /ads by different organization was also assessed :

- $\quad$ Govt. ads

- $\quad$ Business ads (product ads / corporate ads)

- $\quad$ Entertainment ads (Film, Drama, Theatre, concert, others shows)

- $\quad$ Sports ads (by Sports Board or its members)

- $\quad$ Education ads (by educational institutes)

The topics of the news information coverage including the editorial articles were compared with each other. Each topic was compared with the ads given by the segment. The findings have been analyzed to find out if there is any link and also to find out the real contribution of media in the promotion of higher education as mentioned above.

Limitation and constraints of the methodology: The research was limited to print media alone and thus does not include the other major ones e. g. cable, satellite $\mathrm{TV}$, Internet, Telecommunication. The news coverage and ad coverage were assessed visually. The measurements were based on visual calculations. Supplement or weekend editions having pages of size other than the standard size (A4 size) of the newspapers have been excluded from the survey.

TABLE 2

\section{NEWSPAPERS SHOWING TYPE OF COVERAGE}

\begin{tabular}{llll}
\hline Newspaper & News coverage (\%) & Ads (\%) & Others $(\%)$ \\
\hline The Dawn & 52 & 45 & 3 \\
The News & 47 & 41 & 12 \\
The Nation & 50 & 41 & 9 \\
The Jang & 51 & 45 & 4 \\
The Nawa e Waqt & 53 & 43 & 4 \\
The Express & 51 & 39 & 10 \\
\hline
\end{tabular}

Others include cartoons, TV time, horoscope, Obituaries, train timings, weather forecasts, emergency numbers etc. 
TABLE 3

NEWSPAPERS SHOWING NEWS AND AD COVERAGE

\begin{tabular}{lcccccc}
\hline & Dawn & The News & The Nation & Jang & N. Waqat & Express \\
\hline TOPICS & $\%$ & $\%$ & $\%$ & $\%$ & $\%$ & $\%$ \\
NEWS & 52 & 47 & 50 & 51 & 53 & 51 \\
Political/social news & 34 & 32 & 35 & 33 & 35 & 34 \\
Business news & 9 & 5 & 5 & 5 & 6 & 7 \\
Entertainment news & 4 & 6 & 6 & 9 & 5 & 6 \\
Sports news & 3 & 4 & 3 & 3 & 6 & 4 \\
Education news & 2 & - & 1 & 1 & 1 & - \\
ADS & 45 & 41 & 41 & 45 & 43 & 39 \\
Govt ads & 10 & 9 & 10 & 11 & 12 & 9 \\
Business Ads & 22 & 20 & 22 & 24 & 20 & 21 \\
Entertainment Ads & 3 & 8 & 5 & 5 & 6 & 6 \\
Sports Ads & - & - & - & - & - & - \\
Education Ads & 6 & 4 & 4 & 5 & 5 & 3 \\
Others & 3 & 12 & 9 & 4 & 4 & 10 \\
\hline TOTAL & 100 & 100 & 100 & 100 & 100 & 100 \\
\hline Others & & & & & & \\
\end{tabular}

Others include cartoons, TV time, horoscope, Obituaries, train timings, weather forecasts, emergency numbers etc.

\subsubsection{DETAIL FINDINGS}

- It appears that news dominates the coverage for all i.e. $47 \%$ for The News $50 \%$ for Nation, $51 \%$ for Jang and Express, $52 \%$ for the Dawn and 53\% for Nawa e Waqt. Ads coverage was maximum for Dawn (45\%) and Jang (45\%) followed by Nawa e Waqt $43 \%$, the News $41 \%$, the Nation $41 \%$ and the Express $(39 \%)$. Govt ads for the selected newspapers were $9-12 \%$ of all ads in the respective newspapers.

- Coverage of cartoons, puzzles and horoscope etc indicated by 'others' was maximum for The News $12 \%$ followed by the Express $10 \%$, the Nation $9 \%$, the Jang $4 \%$, Nawa e Waqt $4 \%$ and the Dawn 3\%.

- Political and social news had the maximum coverage in all the newspapers the nation 35\%, Nawa e Waqt 35\%, Dawn 34\%, Express 34\%, Jang 33\% and the News $32 \%$.

- Business news coverage was maximum for Dawn $9 \%$ followed by the Express $7 \%$, Nawa e Waqt $6 \%$ abd all others $5 \%$.

- Entertainment news was maximum for Jang $9 \%$ followed by the News $6 \%$, the Nation $6 \%$, the Express $6 \%$, Nawa e Waqt $5 \%$ and Dawn $4 \%$.

- Sports news coverage was maximum for Nawa e Waqt $6 \%$ followed by the News 4\%, the Express 4\%, the Dawn 3\%, the Nation 3\%, and Jang 3\%. 
- Education news coverage was only $2 \%$ for Dawn, $1 \%$ for The Nation, Jang and Nawa e Waqt, while it was nil or almost nil $(<1 \%)$ for The News and Express.

\subsubsection{DISCUSSION AND ANALYSIS}

It is a common practice in Pakistan that If a certain major newspaper does not cover the government and its activities then the authorities restrict government sponsorship for that paper. Taking into account this information we see that political and social events particularly that of the government receive major coverage. Out of the total ads 20-24\% of the ads were from the industry. Keeping the above mentioned considerations we find industry coverage of 5-9\% as against their ads $20-24 \%$. Ads for entertainment were 3-8\% against their news coverage of 4-9\%. There was no sports ads yet the sports coverage was found to be $3-6 \%$. Ads for education were $3-12 \%$ but its news coverage was $1-2 \%$ only. For 'The News' and 'Express' there was almost no education coverage $(<.5 \%)$ at all.

The author discussed with the editorial management of 3 newspapers regarding the coverage of education in general and events (e. g. convocation) of universities in particular. The event (e. g. convocation) of public sector universities are covered only when some hierarchy from the bureaucracy is involved. But the private sector universities are objectively neglected. Their argument is that they cannot promote activities of commercially run private sector universities. But the fact is that the educational entrepreneurs are serving the nation through these private universities and without the support of media these universities can not remain motivated in terms of their quality contribution for sharing the burden of educating the nation. These caring entrepreneurs, philanthropists and corporate citizens of the country in need of support, encouragement and motivation. HEC (Higher Education Commission) of Pakistan itself requires appreciation and motivation for the hard work that they are doing for promoting higher education in Pakistan. Without the support of media it is an uphill task to spread education to the mass population and further improve its quality. The media has a double role: first to support the universities in their constructive role and then to make them accountable for their desired performance. Additionally the awareness of benefits of higher education need to be created on an ongoing uninterruptedly.

\subsection{HOUSEHOLD SURVEY}

A survey was conducted using one hundred households of Karachi with a predesigned questionnaire. Objectives of the survey were to assess the time spent by household ladies for media watching / reading and their opinion about the degree of influence of these media on the mind of general public. Questions were asked to common acquaintances through telephones. In the convenient sample all the respondents were ladies of their houses. All ladies were married and having children of their own. All were having qualifications matric and above, while majority were graduates and some 
of them masters too. Some of them were employed including employment at school as teachers or associated work. The households having income between Rs. 30,000 to 100,000 were included in the survey. Rejected and incomplete interviews were completed later to make it 100 .

The following questions were asked:

Q. What are your past time / hobbies?

A. This was an open ended question. Answers were categorized at the time of compilation. Book reading included novels and mainly Urdu novels. There were also a variety of newspapers. A total of 16 newspapers were reported. Major ones were the ones we included for our previous survey (i.e. the Dawn, the News, the nation, the Jang, the Nawa e Waqt and the Express). Magazines included monthly periodicals (e. g. Sabrang Digest, Khawateen Digest, Readers Digest etc.) as well as weekly ones (e. g. Mag, Akhbar e Jahan, Family Magazine etc).

Q. How much time do you usually spend on your particular hobby / pastime on a daily basis?

A. The result is mentioned in Table 4 .

TABLE 4

Time spent by household ladies on a daily basis for mass media

\begin{tabular}{lccccc}
\hline & $\begin{array}{c}\text { None } \\
\text { No / \% }\end{array}$ & $\begin{array}{c}<\text { 1hour } \\
\text { No / \% }\end{array}$ & $\begin{array}{c}\text { 1-2hours } \\
\text { No / \% }\end{array}$ & $\begin{array}{c}\text { 3-5hours } \\
\text { No / \% }\end{array}$ & $\begin{array}{c}>\mathbf{5} \text { hours } \\
\text { No / \% }\end{array}$ \\
\hline Book reading & 87 & 12 & 1 & & \\
Newspaper & 60 & 19 & 21 & & \\
Magazine & 27 & 54 & 9 & 10 & \\
Music listening & 18 & & 16 & 39 & 27 \\
Radio listening & 25 & & 45 & 30 & \\
Movie viewing & 33 & & 29 & 16 & 22 \\
TV viewing & & 36 & 16 & 54 & 1 \\
Internet & 47 & 45 & 21 & 5 & \\
Mobile telephone & 29 & & & &
\end{tabular}

Any other (Please mention)

In your opinion up to what extent these entertaining exercises influence the minds of general public to act or behave the way it is advised or recommended. 
TABLE 5

Media type influencing the minds of general public as mentioned by the respondents

\begin{tabular}{lccccc}
\hline & $\begin{array}{c}\text { Does not } \\
\text { influence } \\
\text { at all } \\
\%\end{array}$ & $\begin{array}{c}\text { Up to } \\
\text { some extent }\end{array}$ & $\begin{array}{c}\text { Up to } \\
\text { an extent }\end{array}$ & $\begin{array}{c}\text { Up to a great } \\
\text { extent }\end{array}$ & $\begin{array}{c}\text { Influence } \\
\text { totally }\end{array}$ \\
\hline Book reading & & 7 & $\%$ & $\%$ & $\%$ \\
Newspaper & & 20 & 11 & 59 & 30 \\
Magazine & 58 & 15 & 57 & 30 & 23 \\
Music listening & 13 & 39 & 27 & & 2 \\
Radio listening & 33 & 33 & 48 & & \\
Movie viewing & 4 & 14 & 32 & & \\
TV viewing & & 49 & 42 & & \\
Internet & 34 & 37 & & \\
Mobile telephone & & & 46 & & \\
Any other (Please mention) & & & & \\
\end{tabular}

Limitations Of The Survey: The sampling was based on convenience. TV viewing included the film shown on different channels of TV and thus could not be exactly separated from the non film TV viewing. There was no separate question to differentiate between the two.

\subsection{Detail Findings \\ For Table 4}

- $\quad 99 \%$ of the respondents replied that they spend either no time or spend less than one hour in reading books.

- $60 \%$ of the respondents replied that they spend no time in reading daily newspapers, while rest of the $40 \%$ replied that they read newspaper for up to 2 hours daily.

- $81 \%$ of the respondents replied that they spend no time or less than an hour in reading magazines.

- $66 \%$ of the respondents replied that they spend 3 or more hours in listening music. $16 \%$ replied that they spend $1-2$ hours while $18 \%$ replied that they don't listen to music at all.

- $30 \%$ of the respondents replied that they listen to radio for 3-5 hours while $45 \%$ of the respondents replied that they spend 1-2 hours in listening radio programs. $25 \%$ replied that they don't listen to radio at all.

- $38 \%$ of the respondents replied that they spend 3 or more hours in viewing movies. $29 \%$ replied that hey spend $1-2$ hours in viewing movies. $33 \%$ replied that they don't view movie at all.

- $75 \%$ of the respondents replied that they spend 3 or more hours in viewing TV, while the rest $(25 \%)$ replied that they spend $1-2$ hours in viewing TV.

- $83 \%$ of the respondents replied that their time for using Internet was nil or up to a maximum of 1 hour. 16\% said that their Internet time was 1-2 hours.

- $29 \%$ of the respondents said that they do not spend any time on mobile phone, $45 \%$ said that they spend less than one hour and $21 \%$ said that they spend 12 hours, while $5 \%$ said that the spend 3-5 hours on mobile telephones. 


\section{For Table 5}

- As high as $89 \%$ of the respondents think that books influence the mind either up to a great extent or totally to act or behave the way it is advised or recommended.

- $93 \%$ of the respondents think that newspapers influence the mind either to an extent or to a great extent to act or behave the way it is advised or recommended

- $80 \%$ of the respondents think that magazines influence the mind up to an extent or up to a great extent.

- $73 \%$ of the respondents think that listening music either does not influence the mind at all or influence up to some extent to act or behave the way it is advised or recommended. $27 \%$ of the respondents think that listening t music influence the minds up to an extent.

- $87 \%$ of the respondents think that listening to radio influence the mind up to some extent or up to an extent

- $\quad 33 \%$ of the respondents think that movie viewing does not influence the mind at all, while $65 \%$ think that movie viewing influence the mind of general public either up to some extent or up to a great extent.

- $82 \%$ of the respondents think that TV viewing influence the mind up to an extent or up to a great extent

- $86 \%$ of the respondents think that Internet does influence the mind either up to some extent or up to an extent. 14\% think that Internet influence the mind of general public up to a great extent.

- $80 \%$ of the respondents think that mobile telephone influence the mind up to some extent or up to an extent. $20 \%$ of them think that mobile telephone influence the mind of general public up to a great extent.

\subsubsection{DISCUSSION AND ANALYSIS}

- While $93 \%$ of the respondents spend either no time or less than an hour in reading books, as high as $89 \%$ of the respondents think that books influence the mind best to act or behave the way it is advised or recommended in the book. In Pakistan there is a dearth of reading culture. The bookshops are closed and libraries are deserted. While it is good to see that the respondents do consider book reading as a major source of influencing mind and behavior but at the same time the reading habit is not there.

- The low reading trend for of newspapers and magazines are indicative of a culture distancing from knowledge, more so since the sample size were affluent enough and the household ladies were qualified enough. Such a trend reflects the prevailing lack of reading culture in the society.

- The trend for music listening, radio listening, movie and TV viewing further strengthen the previous finding indicating a passive cultural behavior and a pleasure seeking lifestyle.

\section{CONCLUSIONS}

The people who are considered the authority on their subjects are interviewed and quoted, they are the leaders of the society. The common public follow the leaders. People trust them and their words. For the spread of education, celebrities and academicians / scholars may be involved by the media to voice the need of both education and higher education in terms of quality as well as quantity. Another way of using this technique is 
to use large groups of people. The selected people would discuss a topic creating awareness and knowledge. By doing so they are increasing individual's awareness, and thus stimulating instincts towards a particular issue or item and influencing individual's decision towards the chosen topic. Media need to be committed to share the promotion of education and higher education in Pakistan. A firm commitment with an ongoing long term program would reap dividends in immeasurable terms. Stuart and associates (January 1998) reviewed the convergence between Global Media Networks and Higher Education Provision. According tot heir findings opportunities for the Australian higher education sector include: Strong Postgraduate Programs and Strong Continuing Professional Education Programs. The threat to Australian universities lies not only in the 'pull power' and strong recognition of UK/US universities, but also in maintaining Australia's good reputation in Asia. Australia's current advantage in market terms is a 'first mover' advantage prone to erosion over time. Many argues that the threat to universities lay in 'cherry picking' commercially-attractive courses which currently allow Australian public universities to supplement operating grants. (http://www.dest.gov.au/archive/highered/eippubs/eip97-22/eip9722.pdf). Stuart's findings may be used by us as a guideline for offering Programs at postgraduate level and also to include the courses in the Programs in view of the changing scenario in the international environment. Such offerings may also be revised periodically.

Education is progressively moving to the masses and now it is being exported to the world as a service commodity. In view of the existing global trend it will not be surprising if we see that Pakistani universities are competing with the local campuses of world renowned universities the same way that locally manufactured consumer goods are competing with that of multinationals. Once again the role of media would play its role to convince the local people about the comparative quality of education.

It appears that the society is becoming more a learning market and higher education sector is a premium service provider. Like other services the pros of higher education and cons of not having it will be the talk of the future times in Pakistan . In view of the incoming trend of foreign universities in Pakistan it is imperative that the situation is dealt with head on with the involvement of mass media.

The potential impact of new technologies is unavoidable and need to be incorporated in the curriculum. While the government need to regulate the framework and extend the registration and accreditation process to new and emerging higher education centers, media at the same time need to be vigilant about the dissemination of knowledge on the set parameters. The presence of consumer protection regulations are not new, neither the presence of consumer activist forum. Such regulations and education activists need to be developed for higher educations sector as well.

The concept of virtual universities and online education are spreading rapidly. Distance learning program is already in practice. This practice may be further extended to online programs. Pakistan need to jump in as soon as possible and take the early mover advantage. The basic function of a university is knowledge creation. Universities may be assessed periodically on the basis of research and knowledge creation for the society having some value added benefit on empirical terms. 


\section{REFERENCES}

Birrell, B. and Edwards, D. (2007, February 28) Squandering our young's potential.. The Australian, Higher Education Supplement pp 38-39.

Birrell, R. and Rapson, V. (2006) Clearing the myths away: Higher education's place in meeting workforce demands Dusseldorp Skills Forum, Melbourne.

Chelvan S. Arul and Viswanathan D. 2006. Role and Effectiveness of Electronic Media in Higher Education with Special Reference to Tamilnadu. Turkish Online Journal of Distance Education-TOJDE July 2006 ISSN 1302-6488 Volume: 7 Number: 4 Article: 2

Cunningham Stuart, Tapsall Suellen, Ryan Yoni, Stedman Lawrence, Bagdon Kerry and Flew Terry. January 1998. New Media and Borderless Education: A Review of the Convergence between Global Media Networks and Higher Education Provision. Evaluations and Investigations Program, Higher Education Division. Department of Employment, Education, Training and Youth Affairs. Commonwealth of Australia 1997. Commonwealth Information Services, Australian Government Publishing Service, Canberra ACT 2601. http://www.dest.gov.au/archive/highered/eippubs/eip97-22/eip9722.pdf

Daniel Edwards. 2008. What happens when supply lags behind demand? Disadvantaged students and the ever increasing competition for university places. Journal of Higher Education Policy and Management, Volume 30, Issue 1 February 2008 , pp 3-13

Govt of Pakistan 2008. Education Statistics. Higher Education Commission (HEC) of Pakistan, 2006.

Ken Freed. Media Vision Journal. http://www.media-visions.com/index.htm

Ken Freed. That's 'Edutainment'. Media \& Education. Media Visions Journal. http://mediavisions.com/ed-edutain.html)

Long, T. (1984, March), "Broadcasting for rural development". Media in Education and Development, 17(1), pp 17-19.

Mian Sarfraz A. 2006. Can entrepreneurial university model help Pakistan leapfrog into the knowledge economy? Some reflection. Proceedings of 1st International Conference on Assessing Quality in Higher Education ICAQHE, 2006; pp 11-13 December 2006; p 397.

Moosa Kamran. 2006. Quality assurance in higher education: Successful approaches for improving quality in colleges and universities. Proceedings of 1st International Conference on Assessing Quality in Higher Education ICAQHE, 2006; pp 11-13 December 2006; pp 97-98 and pp 108-09.

Woodhouse David. 2006. The role of quality assurance agencies in higher education in the 21st Century. Proceedings of 1st International Conference on Assessing Quality in Higher Education ICAQHE, 2006; pp 11-13 December 2006; pp 1. 